\title{
Identification of TPD52 and DNAJB1 as two novel bile biomarkers for cholangiocarcinoma by iTRAQ-based quantitative proteomics analysis
}

\author{
HONGYUE REN ${ }^{1 *}$, MINGXU LUO $^{2,3^{*}}$, JINZHONG CHEN $^{4}$, YANMING ZHOU $^{5}$, \\ XIUMEI $\mathrm{LI}^{4}$, YANYAN ZHAN ${ }^{6}$, DONGYAN $\mathrm{SHEN}^{7}$ and $\mathrm{BO} \mathrm{CHEN}^{3}$
}

\begin{abstract}
${ }^{1}$ Department of Pathology, The Affiliated Southeast Hospital of Xiamen University, Zhangzhou, Fujian 363000;
${ }^{2}$ Department of Gastrointestinal Surgery, Xiamen Humanity Hospital; Departments of ${ }^{3}$ Gastrointestinal Surgery, ${ }^{4}$ Endoscopy Center and ${ }^{5}$ Hepatopancreatobiliary Surgery, Xiamen Cancer Hospital, The First Affiliated Hospital of Xiamen University, Xiamen Fujian 361003; ${ }^{6}$ Cancer Research Center, Xiamen University Medical College, Xiamen, Fujian 361002;

${ }^{7}$ Biobank, Xiamen Cancer Hospital, The First Affiliated Hospital of Xiamen University, Xiamen, Fujian 361003, P.R. China
\end{abstract}

Received December 17, 2018; Accepted September 26, 2019

DOI: $10.3892 /$ or.2019.7387

\begin{abstract}
Cholangiocarcinoma (CCA) represents a type of epithelial cancer with a late diagnosis and poor outcome. However, the molecular mechanisms responsible for the development of CCA have not yet been fully identified. Thus, in this study, we aimed to elucidate some of these mechanisms. For this purpose, isobaric tags for relative and absolute quantification (iTRAQ) was performed to analyze the secretory proteins from the 2 CCA cell lines, TFK1 and HuCCT1, as well as from a normal biliary epithelial cell line, human intrahepatic biliary epithelial cells (HiBECs). Differentially expressed proteins (DEPs) were identified and biological process analysis was performed according to the Gene Ontology (GO) functional classification annotation and KEGG metabolic pathway map analysis. tumor protein D52 (TPD52) and DnaJ heat shock protein family (Hsp40) member B1 (DNAJB1) were validated using RT-qPCR, western blot analysis and immunohistochemistry. In total, 778 proteins were identified as DEPs. Following validation, TPD52 and DNAJB1 were used for further analysis. The expression levels of TPD52 and DNAJB1 were elevated in CCA cell lines, tissues and bile samples, suggesting that these
\end{abstract}

Correspondence to: Dr Bo Chen, Department of Gastrointestinal Surgery, Xiamen Cancer Hospital, The First Affiliated Hospital of Xiamen University, 55 Zhenhai Road, Xiamen, Fujian 361003, P.R. China

E-mail: chenbo7892@xmu.edu.cn

Dr Dongyan Shen, Biobank, Xiamen Cancer Hospital, The First Affiliated Hospital of Xiamen University, 55 Zhenhai Road, Xiamen, Fujian 361003, P.R. China

E-mail: shendongyan@163.com

*Contributed equally

Key words: cholangiocarcinoma, tumor protein D52, DnaJ heat shock protein family (Hsp40) member B1, iTRAQ, biomarker proteins may contribute to tumor pathogenesis. In addition, the expression levels of TPD52 and DNAJB1 were found to be closely associated with the clinical parameters and prognosis of patients with CCA. On the whole, the findings of this study indicate that TPD52 and DNAJB1 may serve as novel bile biomarkers for CCA.

\section{Introduction}

Cholangiocarcinoma (CCA) is the second most frequent primitive liver malignant tumor originating from the biliary tract epithelium. According to their anatomical location, CCAs are currently classified as intrahepatic (iCCA), perihilar (pCCA) and distal CCA (dCCA) (1). CCA is associated not only with a lack of susceptibility to chemotherapeutic drugs, but also with the development of drug resistance in chemotherapy. Hence, at present, surgical resection is the only treatment strategy for this disease. However, due to the specific anatomic position of this type of tumor, the majority of patients with CCA are already at the advanced stages of the disease at the time of diagnosis, and are thus ineligible for surgery (2). However, even after radical resection, the post-operative recurrence rates of patients with CCA range between 67 and 75\% (3). The 5-year survival rate for patients with CCA remains $<5 \%$ (4).

It is well known that CA199 serves as a tumor-associated antigen and may be useful for the diagnosis of various types of cancer $(5,6)$. Nevertheless, the use of CA199 in the diagnosis of CCA is difficult due to the lack of specificity. Therefore, the identification of novel effective tumor biomarkers and therapeutic strategies with which to improve the diagnosis, therapy and prognosis of patients with CCA is urgently required.

As the development of CCA occurs at the biliary epithelium and tumor-related proteins are secreted or shed into the bile, the identification of markers in bile is a straightforward approach for the accurate detection of CCA (7). Endoscopic retrograde cholangiopancreatography $(\mathrm{ERCP})$ is a well-known technique, which provides information on stricture site, length and the presence of mucosal irregularity or shouldering during 
therapeutic procedures. Importantly, ERCP is beneficial for the diagnosis of CCA, and provides the option of tumor sampling for cytology (8). However, the variable composition of secretory proteins in bile poses tremendous technical challenges for the identification of relevant biomarkers for CCA.

The technique of isobaric tags for relative and absolute quantitation (iTRAQ) combined with liquid chromatography-tandem mass spectrometric (LC-MS/MS) is emerging as one of the most important proteomics approaches, and has become a novel tool for the detection of protein expression in cancer cell lines and tumor-related tissues $(9,10)$. iTRAQ-based proteomics is applied to protein samples with a more robust labeling and can detect 8 samples in parallel (11); it can also decrease the potential variation in multiple mass spectrometry detection. More importantly, iTRAQ has the advantage of providing detailed protein expression profiles and high resolution, while reducing experimental error (12). Hence, it has been widely used for the identification of candidate biomarkers for multiple tumors.

In this study, quantitative proteomics analysis using the iTRAQ in combination with LC-MS/MS was performed to identify CCA cell-enriched secretory proteins compared with those in a normal biliary epithelial cell line. In total, 778 proteins were identified as differentially expressed proteins (DEPs) and were classified according to biological process, cellular component and as molecular function using bioinformatics analyses. Finally, we confirmed tumor protein D52 (TPD52) and DnaJ heat shock protein family (Hsp40) member B1 (DNAJB1) as biomarkers, which were upregulated in CCA cells, culture supernatants, tissues and bile samples. In addition, the overexpression of TPD52 and DNAJB1 was found to be associated with the clinical parameters and prognosis of patients with CCA.

\section{Materials and methods}

Reagents. RPMI-1640 medium, fetal bovine serum (FBS) and penicillin were purchased from Invitrogen; Thermo Fisher Scientific. Antibodies against TPD52, transforming acidic coiled-coil-containing protein 3 (TACC3), Ephrin A1(EFNA1), transferrin (TRF) and $\beta$-actin were obtained from Abcam. DNAJB1, LDH, trypsin and goat anti-rabbit/mouse secondary antibodies conjugated to horseradish peroxidase were from Sigma-Aldrich. The Total RNA extraction kit, SYBR-Green detection system and the Bradford protein assay kit were purchased from Tiangen Biotech. The ultrafiltration device, ECL reagent and polyvinylidene difluoride (PVDF) were from Millipore. The DAB detection kit was from Maixin Biotech. The iTRAQ labeling Reagents kit was from Applied Biosystems.

Patients and tissue samples. A tissue microarray (TMA) of CCA was obtained from National SOBC Biobank, which included 127 CCA specimens and 9 samples of normal biliary epithelial tissues. Among the 127 CCA specimens, 61 patients were $\leq 60$ years old and 66 patients were $>60$ years old. In total, 80 patients were males and 47 were females. Of these patient samples, 78 were characterized as low differentiation (I, I-II and II) and 49 as high differentiation (II-III, III and III-IV). In total, 100 patients had iCCA and 27 patients had extrahepatic CCA. As regards the tumor sizes, 59 patients had tumors $\leq 5 \mathrm{~cm}, 58$ had tumors $>5 \mathrm{~cm}$ and in 10 patients, tumor size was unknown. Vessel invasion was found in 100 patients. Information regarding TNM stage and clinical stage was obtained for the patients. Fresh bile samples of 29 patients with CCA and 8 healthy individuals were collected at the First Affiliated Hospital of Xiamen University between January 2015 and December 2017. This study was approved by the Ethics Committee of the First Affiliated Hospital of Xiamen University. Informed consent was obtained from all individual participants included in the study.

Cells and cell culture. Normal biliary epithelial [human intrahepatic biliary epithelial cells (HiBECs)] cells were obtained from PriCells and were cultured in PriCells medium. The human cancer cell lines (cancers of the hepatobiliary system), QBC939 (CCA), SK-ChA-1 (CCA), MZ-ChA-1 (gallbladder cancer, for comparison), TFK1 (CCA) and HuCCT1 (CCA), were routinely cultured in RPMI-1640 medium containing $10 \% \mathrm{FBS}$ and $100 \mathrm{U} / \mathrm{ml}$ penicillin. The cells were maintained at $37^{\circ} \mathrm{C}$ in a humidified atmosphere under $5 \% \mathrm{CO}_{2}$. The human CCA cell line QBC939 was kindly provided by Professor Shu-Guang Wang from Southwest Hospital, the Third Military Medical University, Chongqing, China. The cell lines HuCCT1, Sk-ChA-1, MZ-ChA-1 and TFK1 were kindly provided by Chun-Dong Yu, laboratory of Xiamen University, Xiamen, China. HiBECs were purchased from Cell Bank of the Type Culture Collection of Chinese Academy of Sciences (HUM-CELL-0035).

CCA cell culture supernatant collection. The same number cells, including the 4 CCA cell lines, a gallbladder cancer cell line (MZ-ChA-1) and a biliary epithelial cell line (HiBECs) were seeded in 6-well plates overnight and then cultured in serum-free cell culture medium for $24 \mathrm{~h}$ at $37^{\circ} \mathrm{C}$. The cell culture supernatants containing secretory proteins were collected and centrifuged to remove cells. Following centrifugation at $4,000 \times \mathrm{g}$ for $30 \mathrm{~min}$ at $4^{\circ} \mathrm{C}$ to concentrate using ultrafiltration with $3-\mathrm{kDa}$ filters, the cell culture supernatants were transferred to new tubes and then stored at $-70^{\circ} \mathrm{C}$. The CCA cell culture supernatants were referred to as TRF. LDH was used as a quality control.

Bile secretory protein collection. The bile samples were centrifugated at $12,000 \mathrm{x}$ g for $30 \mathrm{~min}$ at $4^{\circ} \mathrm{C}$ to remove impurities, and the supernatants containing secretory proteins were then transferred to a clean tube. If the samples have more impurities following the above-mentioned strategy, repeated centrifugation is then necessary. The protein concentration was determined using the Bradford protein assay kit according to the instructions of the manufacturer. The CCA bile samples were referred to TRF.

Western blot analysis. Cell lysates containing equal amounts of proteins underwent $8 \%$ SDS-polyacrylamide gel electrophoresis followed by transfer onto PVDF membranes. After blocking non-specific binding sites with 5\% dried skimmed milk solution for $1 \mathrm{~h}$ at room temperature, the membranes were incubated overnight at $4^{\circ} \mathrm{C}$ with primary antibodies (TPD52, 1:10,000 dilution, ab155296, Abcam; DNAJB1, 1:500 
dilution, SAB2100604, Sigma-Aldrich; TACC3, 1:500 dilution, ab138262, Abcam; Ephrin A1, 1:500 dilution, ab199697, Abcam; $\beta$-actin, 1:1,000 dilution, ab227387, Abcam). The membranes were then incubated with secondary antibodies conjugated to horseradish peroxidase (against mouse, 1:10,000 dilution, A9917, Sigma-Aldrich; against rabbit, 1:5,000 dilution, A9169, Sigma-Aldrich) for $1 \mathrm{~h}$ at room temperature and the signals were finally detected with ECL system. $\beta$-actin was used as a loading control, and the data were quantitatively measured using ImageJ software (version 1.48; National Institutes of Health).

Protein digestion and ITRAQ labeling. Secretory proteins of CCA cells were extracted as described above. iTRAQ labeling was performed according to the manufacturer's protocol. Briefly, $100 \mu \mathrm{g}$ proteins of each sample were reduced and alkylated, and subsequently digested with trypsin overnight at $37^{\circ} \mathrm{C}$. Sequentially, 3 iTR AQ regents (117, 118 and 119) were used to label TFK1, HiBECs and HuCCT1, respectively. Finally, the samples were lyophilized.

LC-MS/MS analysis. The iTRAQ samples were analyzed using LC-MS/MS. Briefly, labeled samples were pooled and fractionated by strong cation exchange (SCX) chromatography. The mixed peptides were reconstituted with buffer A $(10 \mathrm{mM}$ $\mathrm{KH} 2 \mathrm{PO} 4$ in $25 \%$ acetonitrile, $\mathrm{pH} 3.0)$. Separation was carried out using a linear binary gradient of 0-100\% buffer B (buffer B was buffer A containing $2 \mathrm{M} \mathrm{KCl}$ ) at a rate of $1 \mathrm{~m} / \mathrm{min}$ for $10-20 \mathrm{~min}$. The absorbance at 214 and $280 \mathrm{~nm}$ was monitored, and a total of 15 fractions were collected. Following the desalination process, the SCX fractions were dried and dissolved in buffer C $(0.1 \%$ formic acid). They were then separated on a reverse-phase column (75x10 cm, $5 \mu \mathrm{m}, 300$ Á, Agela Technologies) using the Nano-LC system. Subsequently, the elution flow rate was maintained at $400 \mathrm{nl} / \mathrm{min}$ with $5-80 \%$ buffer D (acetonitrile with $0.1 \%$ formic acid) in buffer $\mathrm{C}$ for $100 \mathrm{~min}$. A survey scan was acquired from m/z 350-2000 at a mass resolution of 17,500 full width at half maximum (FWHM) for MS/MS. The experiment was conducted in 3 technical replicates.

Data analysis. All of the obtained mass spectrometry data were processed with Proteome Discoverer 1.3 (Thermo Fisher Scientific) and subsequently searched using MASCOT engine (Matrix Science; version 2.3.01). The parameters were set as follows: Trypsin as digestion enzyme, cysteine carbamidomethylation as a fixed modification, Oxidation (M), Gln $\rightarrow$ Pyro-Glu (N-term Q), iTRAQ 8 plex (K), iTRAQ 8 plex (Y) and iTRAQ 8 plex (N-term) as the variable modification. If the iTRAQ ratio in the CCA cell-enriched secretory proteins compared with the normal biliary epithelial cell line was $>1.2$ and the computed P-value $<0.05$, the protein was considered to be differentially expressed.

Bioinformatics analysis. The Gene Ontology (GO, http://www. geneontology.org/) database was used for the functional annotation among the obtained proteins. The DEPs in GO were divided into 3 categories, including biological process, molecular function and cellular component. The Kyoto Encyclopedia of Genes and Genomes (KEGG, http://www.kegg.jp/) database was used to analyze the cancer pathways of the DEPs.
Reverse transcription-quantitative PCR (RT-qPCR). Total RNA was extracted and reverse transcribed from the cultured cells using RNA simple total RNA extraction kit (Tiangen Biotech) according to the instructions of the manufacturer as previously described (13). qPCR was performed using the SYBR-Green detection system (Tiangen Biotech). The primers for qPCR reactions are listed in Table SI. The relative expression levels of the target genes were according to GAPDH. The qPCR thermocycling conditions were as follows: $95^{\circ} \mathrm{C}$ for $30 \mathrm{sec}, 45 \mathrm{cycles}$ of $90^{\circ} \mathrm{C}$ for $30 \mathrm{sec}, 60^{\circ} \mathrm{C}$ for $20 \mathrm{sec}, 72^{\circ} \mathrm{C}$ for $25 \mathrm{sec}$, and $72^{\circ} \mathrm{C}$ for $15 \mathrm{~min}$. The relative gene expression levels were analyzed using the $2^{-\Delta \Delta C q}$ method (14). All experiments were performed in triplicate.

Immunohistochemistry (IHC)/immunocytochemistry (ICC). After dewaxing in xylene and brought to water through graded alcohols as previously described (13), the $3-\mu$ m-thick tissue microarray sections were incubated with antibodies against TPD52 (1:400 dilution) and DNAJB1 (1:200 dilution) overnight at $4{ }^{\circ} \mathrm{C}$. Appropriate negative controls were performed by omitting the primary antibody. For ICC, the cells planted on the glass slides were cultured in RPMI-1640 medium. After fixing with $4 \%$ paraformaldehyde, the slides were permeabilized with $0.5 \%$ Triton $\mathrm{X}-100$. Subsequent steps were performed as for IHC.

Statistical analysis. All statistical analyses were performed using SPSS 16.0 software (SPSS, Inc.). Data were expressed as the means \pm SEM from at least 3 independent experiments. The Student's t-test was used to analyze two sets of data, and one-way analysis of variance (one-way ANOVA) with Dunnett's post hoc test was performed to compare $>2$ datasets. Pearson's $\chi^{2}$ test was applied to evaluate the association between the patient clinicopathological parameters and the expression protein levels of TPD52 and DNAJB1. Survival curves were evaluated by the Kaplan-Meier method. The log-rank test was used to compare the significant difference between groups. Differences were determined to be statistically significant when the P-value was $<0.05$.

\section{Results}

Quantitative proteomics analysis of secretory proteins by iTRAQ. To identify dysregulated secretory proteins in CCA, iTRAQ quantitative proteomics analysis was performed to compare the CCA cell lines (TFK1 and HuCCT1) with a normal biliary epithelial cell line (HiBECs). The strategy of iTRAQ analysis between the 2 CCA cells (TFK1 and HuCCT1) and the HiBECs is presented in Fig. 1A. When the expression levels of proteins exhibited differences corresponding to $>1.2$ or $<1.2$-fold changes in expression in the TFK1 or HuCCT1 cells compared to the HiBECs, these proteins were regarded as DEPs. As shown in Fig. 1B, a total of 778 DEPs were detected. Briefly, 680 proteins were significantly altered in 2 CCA cell lines (TFK1 and HuCCT1) compared with the HiBECs. Among these, 312 proteins $(40.10 \%)$ displayed a higher expression, whereas 368 proteins (47.30\%) exhibited a lower expression. Furthermore, 98 proteins $(12.60 \%)$ presented a differential expression (either upregulation or downregulation in the 2 CCA cell lines compared to the HiBECs (Fig. 1C). 
A
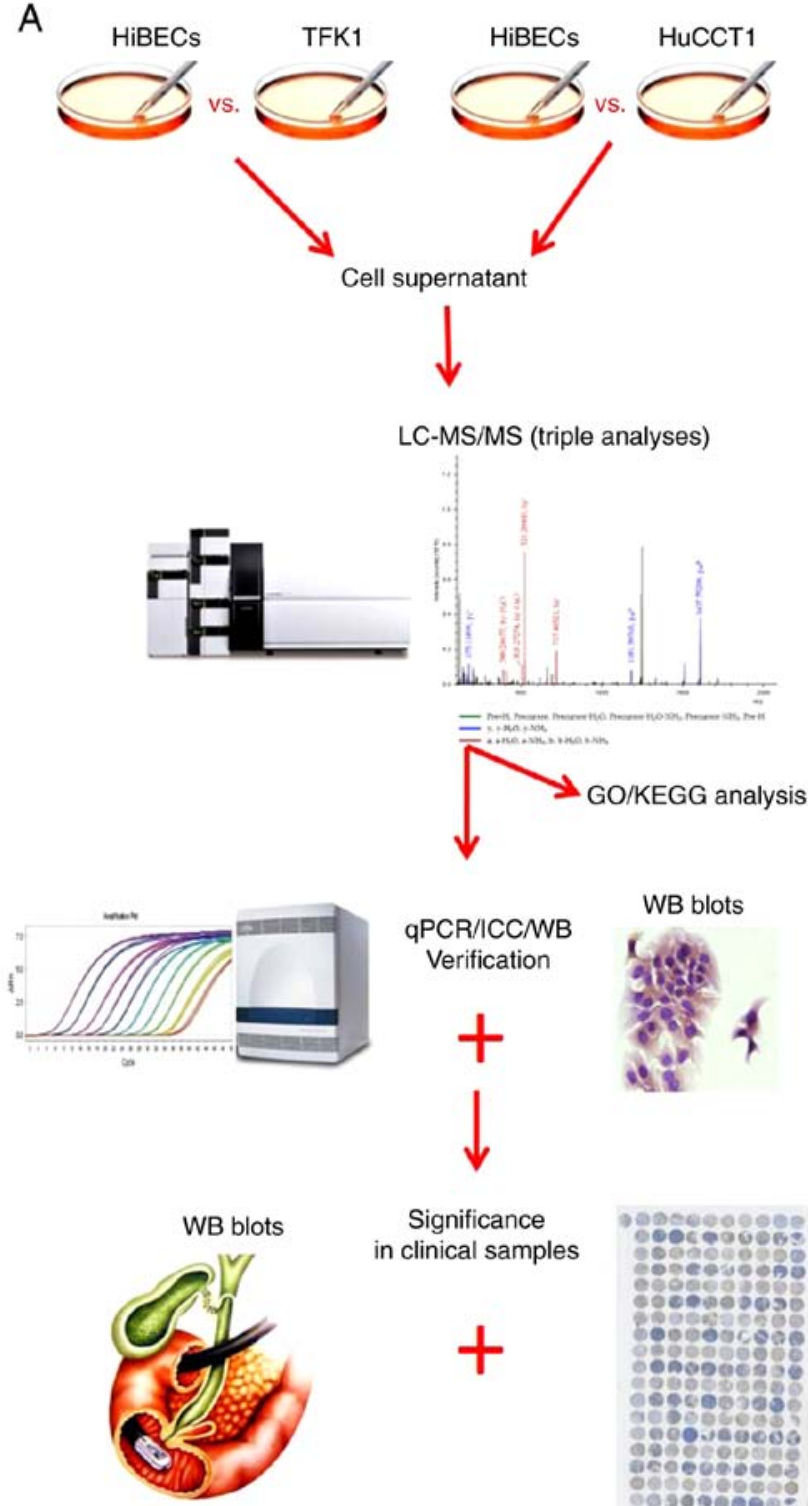

qPCR/ICC/WB Verification

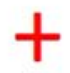

$\sqrt{ }$

WB blots

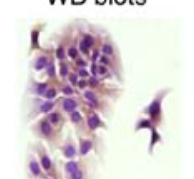

Significance in clinical samples

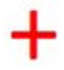

B

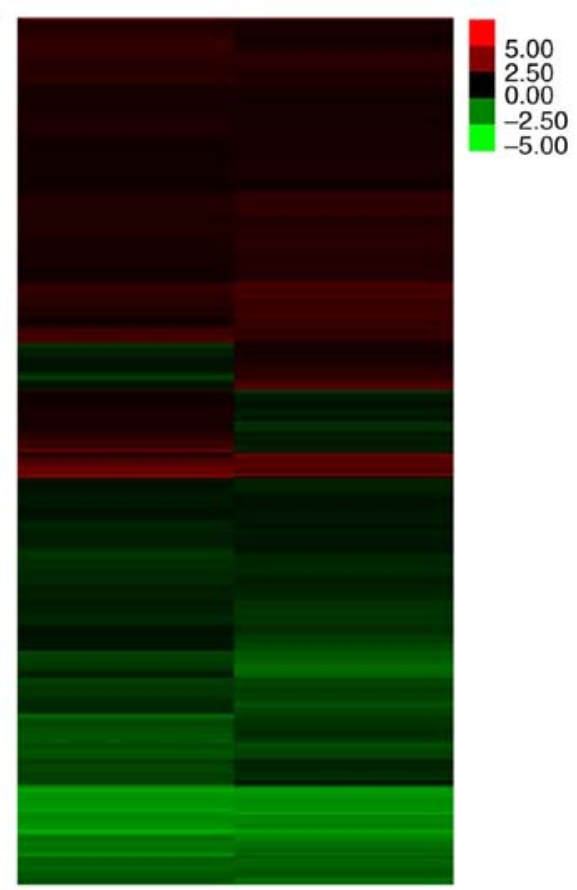

TFK1 vs HiBECS HuCCT1 vs HiBECs

C

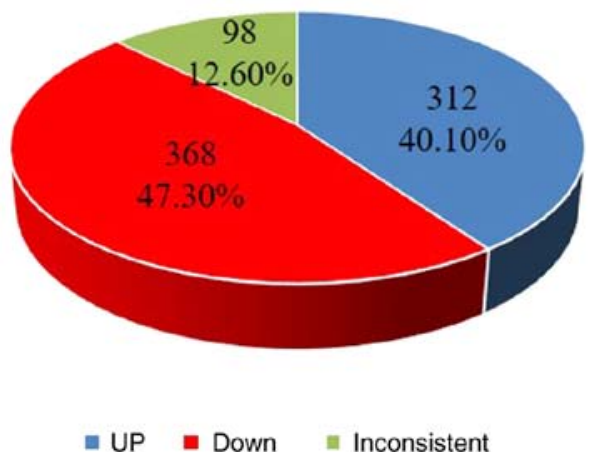

Figure 1. Quantitative proteomics analysis of the secretory proteins in CCA cells and HiBECs. (A) The strategy of iTRAQ analysis between two CCA cells (TFK1 and HuCCT1) and HiBECs. (B) Heatmap of the DEPs in the above-mentioned cell lines. Red indicates a higher expression, green indicates a lower expression and black indicates the same expression levels in the 2 groups. (C) Cluster analysis of DEPs in the above-mentioned cell lines. CCA, cholangiocarcinoma; HiBECs, human intrahepatic biliary epithelial cells; iTRAQ, isobaric tags for relative and absolute quantification; DEPs, differentially expressed proteins.

To reveal the biological functions of the above-mentioned DEPs, we categorized these DEPs between the 2 CCA cell lines and the HiBECs into 3 large groups, including molecular functions, biological processes and cellular components, as well as 60 subgroups depending on their functional annotation in the GO database. As shown in Fig. 2, the results of GO analysis revealed that the DEPs were mainly distributed in the extracellular region. In terms of biological processes, the DEPs mainly participated in macromolecule metabolic process and biological regulation. As regards molecular function, the results indicated that the DEPs were mainly involved in nucleic acid binding and protein binding. In addition, KEGG pathway analysis revealed that the DEPs were associated with processes involved in the development and progression of cancers, such as proliferation, the evasion of apoptosis, differentiation, tissue invasion and resistance to chemotherapy
(Fig. 3). Among these, 22 proteins were found to be connected to carcinogenesis. Most importantly, the expression levels of TPD52, DNAJB1, TACC3 and Ephrin A1 (EFNA1) were upregulated in the CCA cells compared with the HiBECs (Figs. S1-S4). Finally, the above-mentioned 4 candidate DEPs were considered for further analysis.

Validation of TPD52 and DNAJB1 upregulation in CCA cell lines. To confirm the dysregulated expression of 4 DEPs (TPD52, DNAJB1, TACC3 and EFNA1), RT-qPCR and western blot analysis were performed to detect the mRNA and protein expression levels of the 4 markers in 4 CCA cell lines, a gallbladder cancer cell line (MZ-ChA-1) and a biliary epithelial cell line (HiBECs). The results revealed that the mRNA expression levels of the above-mentioned 4 makers in the 4 CCA cell lines and MZ-ChA-1 were all significantly 


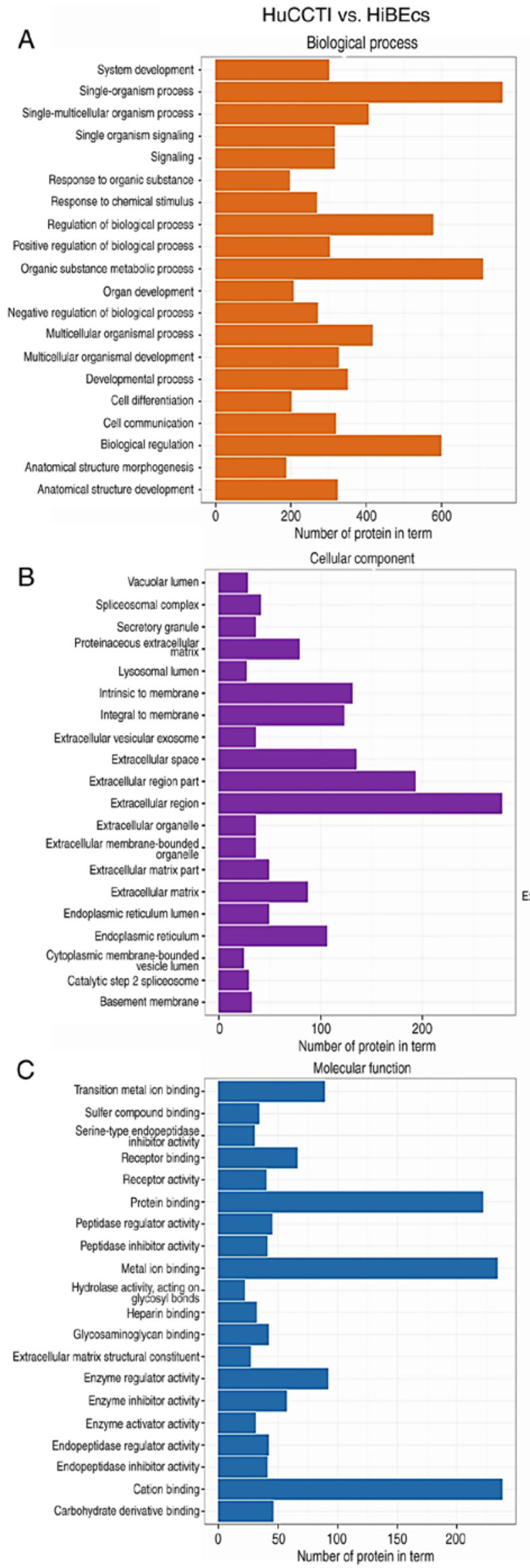

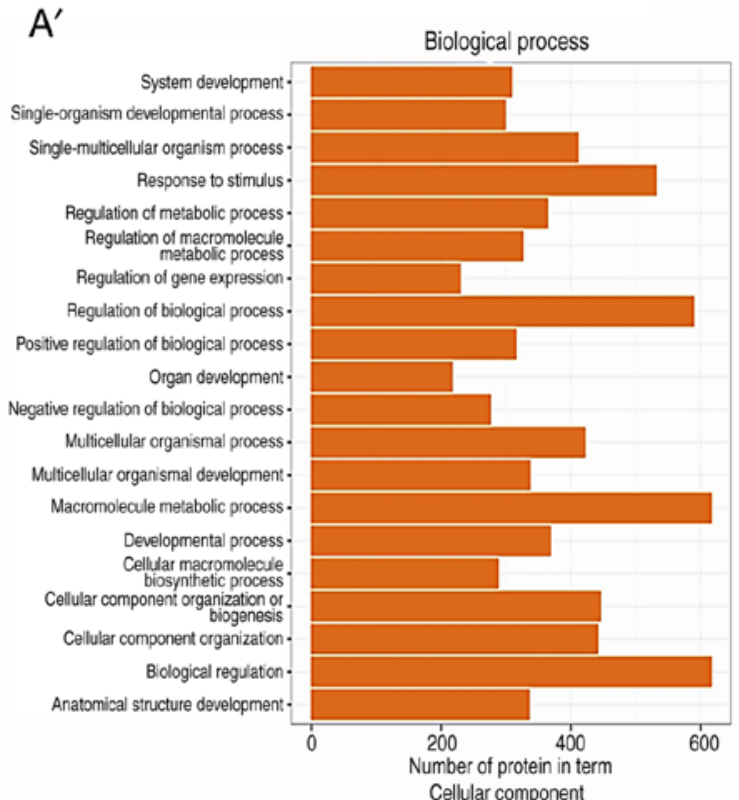

TFK1 vs. HiBECs

$\mathrm{B}^{\prime}$

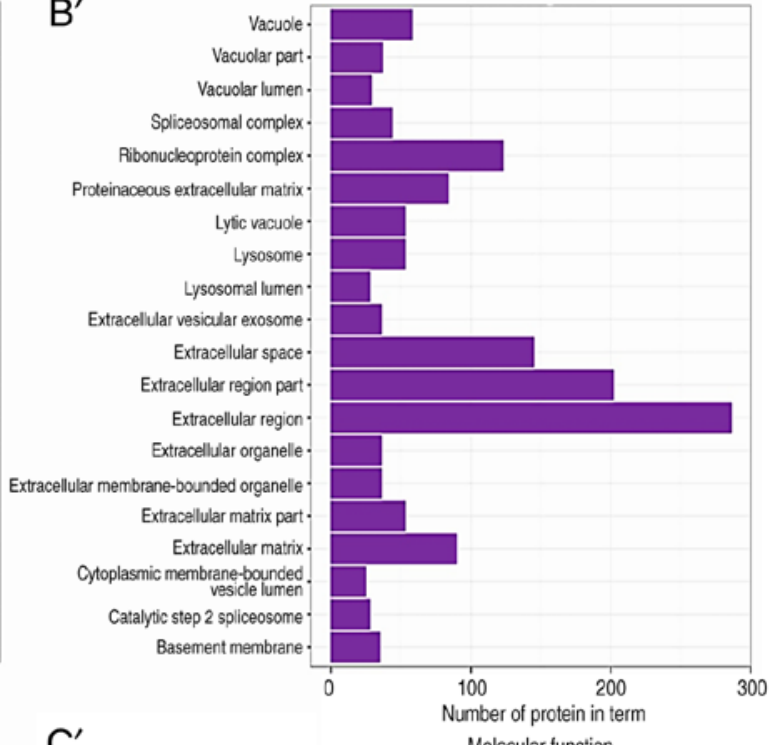

$C^{\prime}$

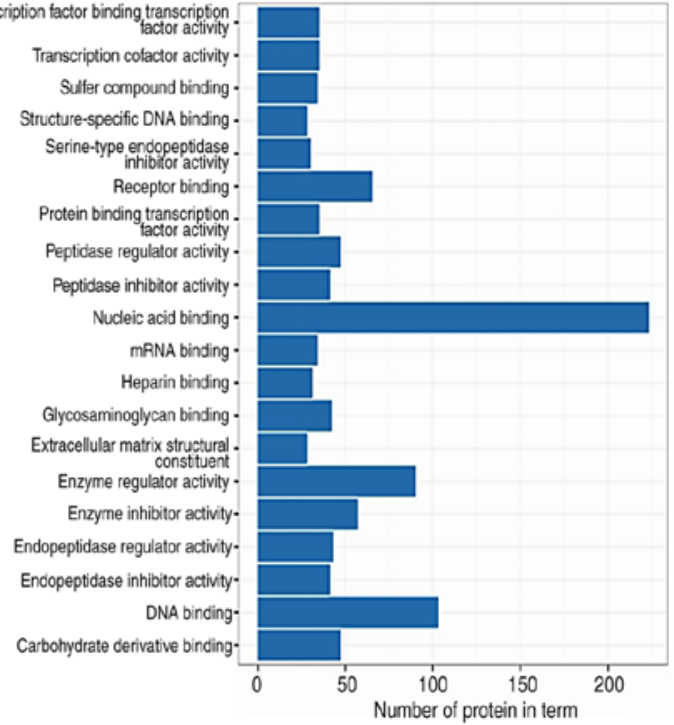

Figure 2. Functional annotation of DEPs in HuCCT1 and TFK1 cells compared with HiBECs. The (A) biological process, (B) cellular component and (C) molecular function classification of DEPs in HuCCT1 cells compared with HiBECs. The (A') biological process, (B') cellular component and (C') molecular function classification of DEPs in TFK1 cellscompared with HiBECs. DEPs, differentially expressed proteins; HiBECs, human intrahepatic biliary epithelial cells. 

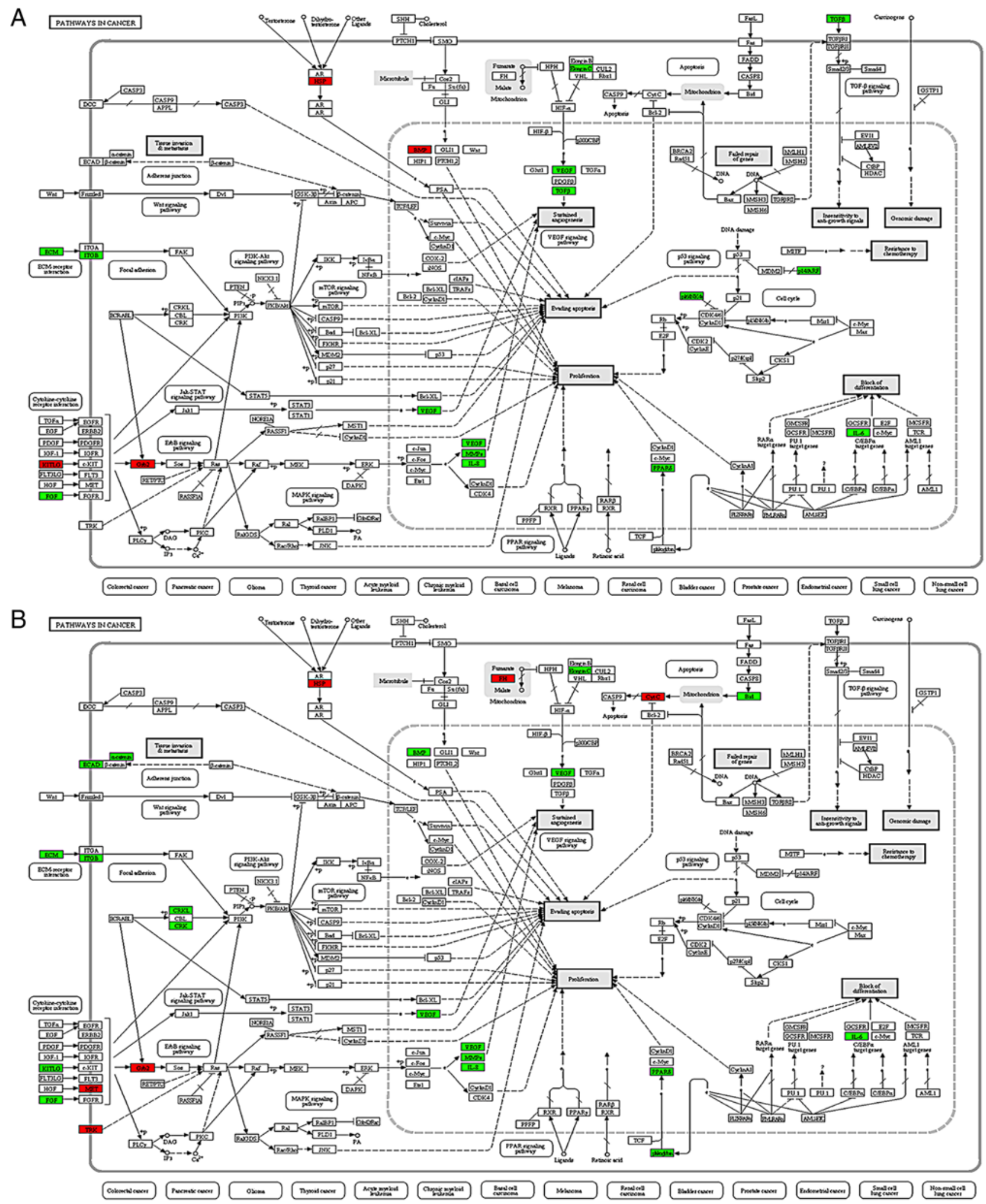

Figure 3. Cancer pathway analysis of DEPs. Cancer pathway analysis of DEPs in (A) HuCCT1 or (B) TFK1 cells compared with HiBECs. Red indicates upregulation and green downregulation. DEPs, differentially expressed proteins; HiBECs, human intrahepatic biliary epithelial cells.

higher than those in the HiBECs cell line (Fig. 4A); however, only the protein expression levels of TPD52 and DNAJB1 were in line with the mRNA results (Fig. 4B). In addition, ICC was performed to observe the cellular localization, which revealed that TPD52 and DNAJB1 were strongly stained and predominantly presented in the cell cytoplasm of the 4 CCA cell lines and MZ-ChA-1, but weakly or not stained in the HiBECs cell line (Fig. 4C). Hence, TPD52 and DNAJB1 were selected for further analysis.

TPD52 and DNAJB1 protein levels are significantly elevated in tissues of patients with CCA. To further evaluate the TPD52 
A
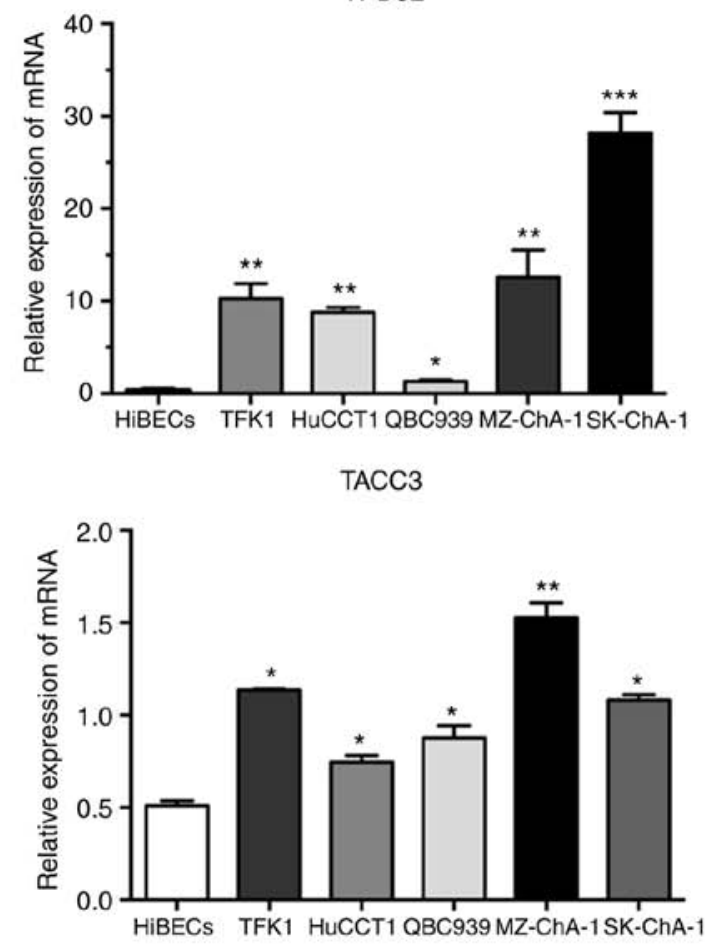

DNAJB1
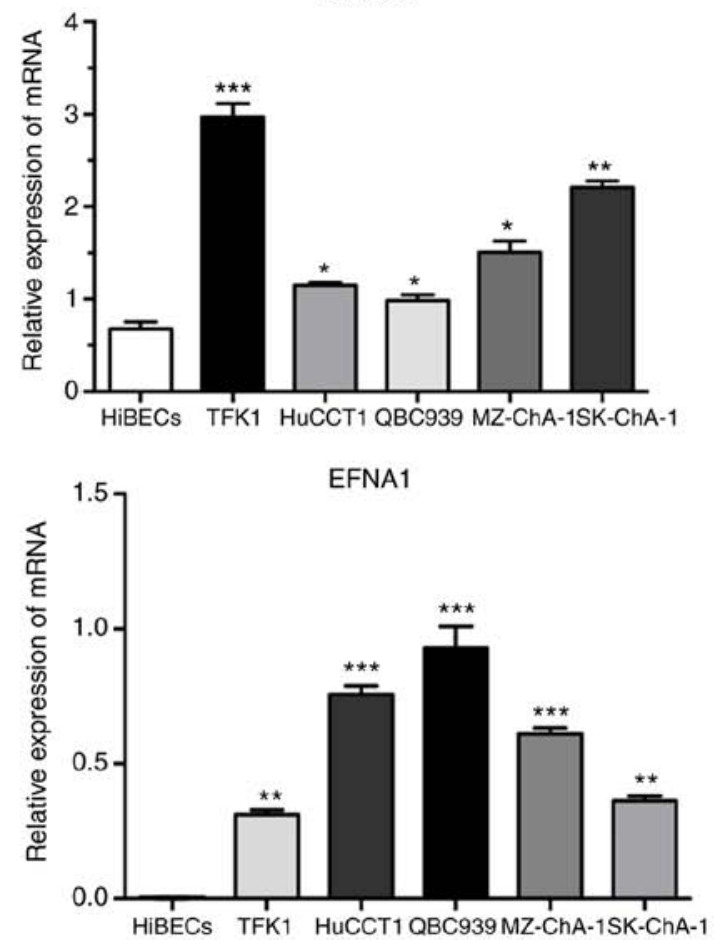

B
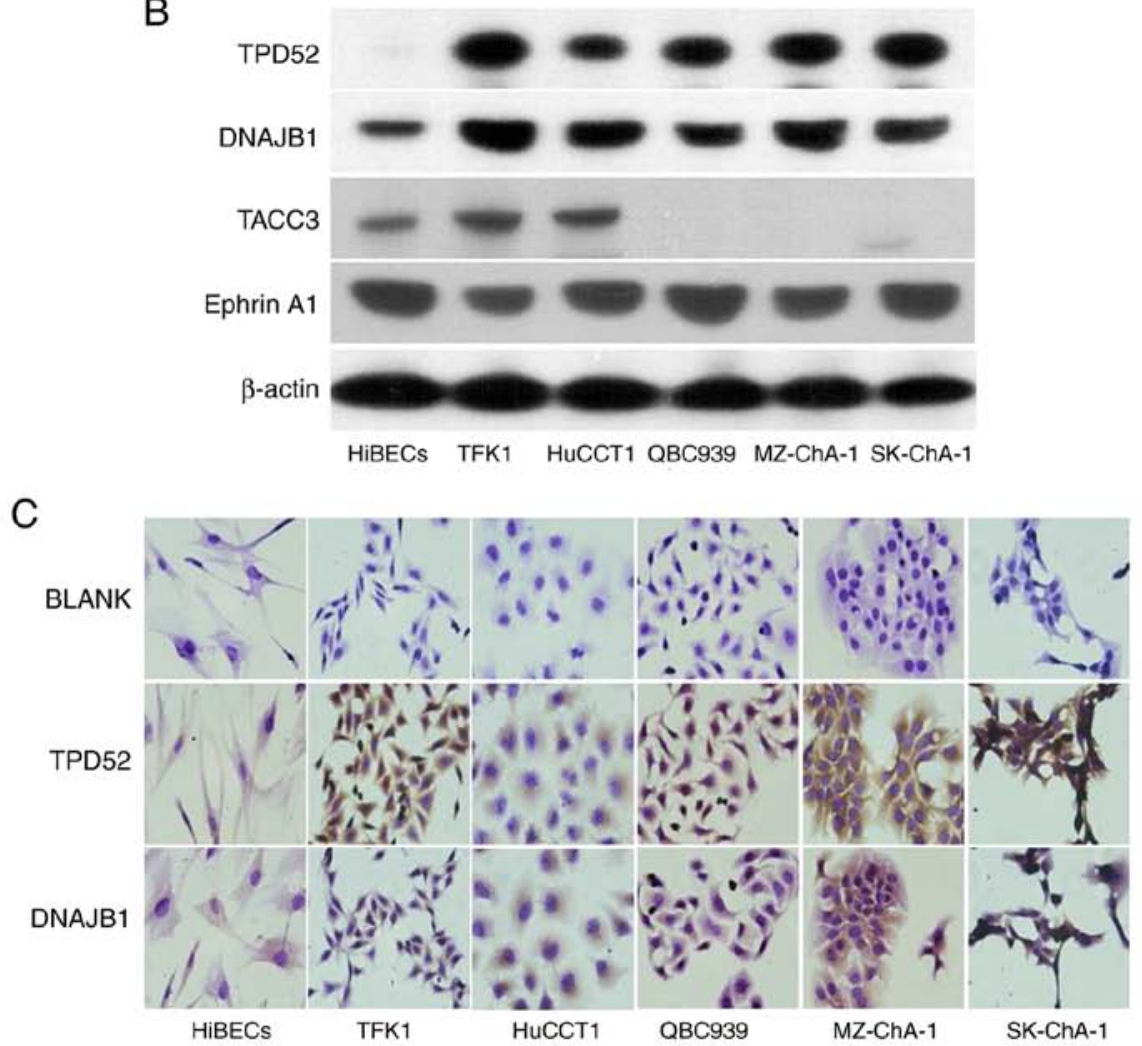

Figure 4. Initial validation of 2 candidate biomarkers. (A and B) mRNA and protein expression levels of TPD52, DNAJB1, TACC3 and Ephrin A1 (EFNA1) in 4 CCA cell lines, a gallbladder cancer cell line (MZ-ChA-1) and a normal biliary epithelial cell line (HiBECs) were respectively analyzed by RT-qPCR and western blot analysis. (C) Representative ICC staining for TPD52 and DNAJB1 in 4 CCA cell lines, MZ-ChA-1 and HiBECs. Magnification, $\mathrm{x} 400$. "P<0.05, ${ }^{* *} \mathrm{P}<0.01$ and ${ }^{* * *} \mathrm{P}<0.001$. CCA, cholangiocarcinoma; HiBECs, human intrahepatic biliary epithelial cells; TPD52, tumor protein D52; DNAJB1, DnaJ heat shock protein family (Hsp40) member B1; TACC3, transforming acidic coiled-coil-containing protein 3.

and DNAJB1 expression levels in clinical CCA tissues, IHC was performed to analyze the expression levels of the 2 markers using a commercial TMA containing an independent cohort of CCA (127 cases) samples. The results revealed that 2 markers, predominantly presenting in the cell cytoplasm, were all strongly stained in the CCA tissues, but weakly or not 

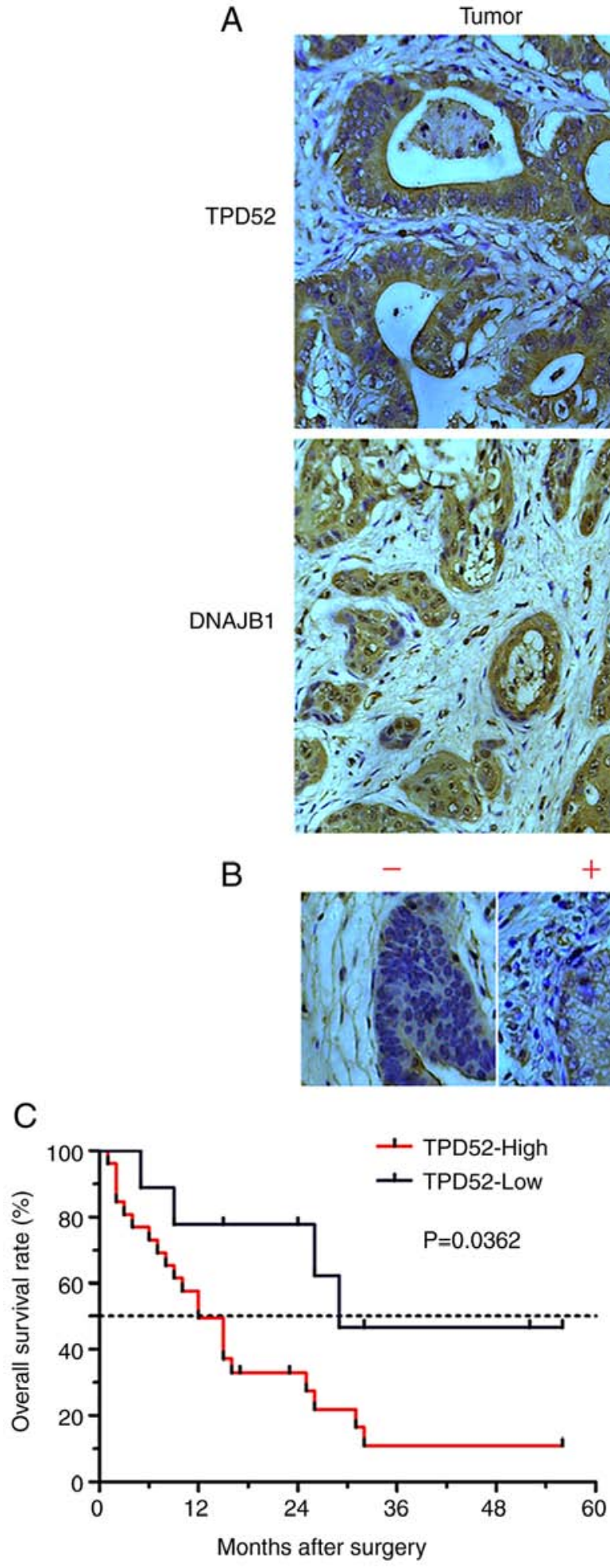

B

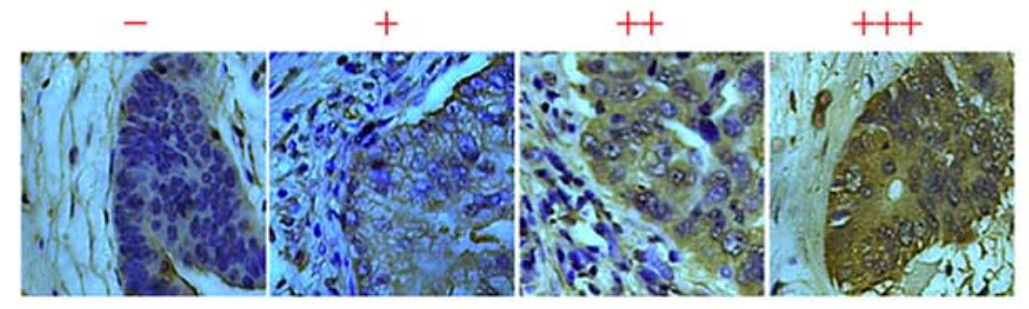

Figure 5. The expression and prognostic significance of TPD52 and DNAJB1 in clinical CCA patient tissues. (A) Representative IHC staining for the 2 identified biomarkers in tumor and noncancerous tissues. (B) Four staining ratings for IHC. (C) Kaplan-Meier survival curve analysis of CCA patients in relation to TPD52 and DNAJB1 expression. The P-value was calculated using the Log-rank (Mantel-Cox) test. Magnification, x400. CCA, cholangiocarcinoma; TPD52, tumor protein D52; DNAJB1, DnaJ heat shock protein family (Hsp40) member B1.

stained in the normal biliary epithelial tissues (Fig. 5A). The staining intensity of the 2 markers in the CCA tissues were categorized as low (- to + ) or high (2+ to $3+$ ) (Fig. 5B). The high expression rate of TPD52 protein in the CCA tissues was $80.3 \%$ (120/127) and that of DNAJB was 78.7\% (100/127); the levels of both these proteins were much higher in the cancerous

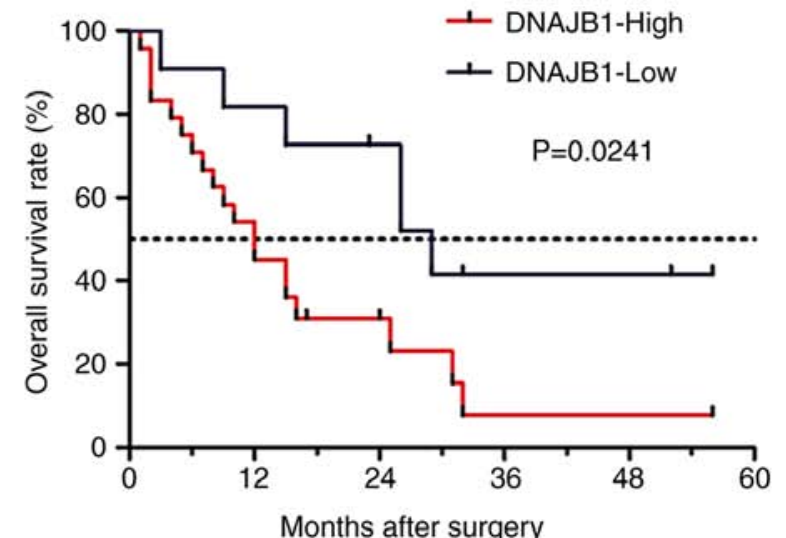

samples than in the normal biliary epithelial tissues $(0 \%)$ $(\mathrm{P}<0.0001$; Table I). These data demonstrated that TPD52 and DNAJB1were markedly overexpressed in CCA tissues.

Associations of TPD52 and DNAJB1 expression with the clinical parameters of patients with CCA. We analyzed the 
Table I. Expression of two tumor markers in CCA and non-cancerous tissues.

\begin{tabular}{|c|c|c|c|c|c|c|c|}
\hline \multirow[b]{2}{*}{ Tissues } & \multirow[b]{2}{*}{ No. of samples } & \multicolumn{2}{|c|}{ TPD52 } & \multirow[b]{2}{*}{ P-value } & \multicolumn{2}{|c|}{ DNAJB 1} & \multirow[b]{2}{*}{ P-value } \\
\hline & & $\mathrm{L}$ & $\mathrm{H}$ & & $\mathrm{L}$ & $\mathrm{H}$ & \\
\hline Tumor & 127 & 25 & 102 & $0.0001^{\mathrm{a}}$ & 27 & 100 & $0.0001^{\mathrm{a}}$ \\
\hline Non-cancerous & 9 & 9 & 0 & & 9 & 0 & \\
\hline
\end{tabular}

L, low expression; H, high expression; CCA, cholangiocarcinoma; TPD52, tumor protein D52; DNAJB1, DnaJ heat shock protein family (Hsp40) member B1. a P-value $<0.05$ was considered to indicate a statistically significant difference.

associations between the expression of TPD52 or DNAJB1 and the clinicopathological parameters of patients with CCA using the $\chi^{2}$ text. The results of statistical analysis are summarized in Table II. We observed that the TPD52 expression level was closely associated with pathological differentiation, $\mathrm{T}$ stage and clinical stage $(\mathrm{P}<0.05)$; however, it was not associated with age, sex, localization, tumor size, vessel invasion, lymph node metastasis and distant metastasis $(\mathrm{P}>0.05)$ in the patients with CCA. The DNAJB1 expression level was closely associated with pathological differentiation, vessel invasion, $\mathrm{T}$ stage, lymph node metastasis and clinical stage $(\mathrm{P}<0.05)$; however, it was not associated with age, sex, localization, tumor size and distant metastasis $(\mathrm{P}>0.05)$ in the patients with CCA (Table II). These results indicated that high expression levels of the 2 proteins may be associated with the development of CCA.

Overexpression of TPD52 or DNAJB1 is associated with the prognosis of patients with CCA. To address the prognostic significance of TPD52 and DNAJB1 in CCA, Kaplan-Meier analysis was performed to evaluate the association between the survival time of patients with CCA and the expression levels of TPD52 or DNAJB1. Of note, the post-operative overall survival rate of patients with a high TPD52 expression (median survival time, 12 months) was lower than that of patients with a low TPD52 expression (median survival time, 29 months) $(\mathrm{P}<0.05)$. In addition, post-operative overall survival rate of patients with a high DNAJB1 expression (median survival time, 12 months) was also lower than that of patients with a low DNAJB1 expression (median survival time, 29 months) $(\mathrm{P}<0.05)$ (Fig. 5C). These results suggest that the overexpression of TPD52 or DNAJB1 may predict a poor prognosis of patients with CCA.

A high level of TPD52 or DNAJB1 in bile is a potential bile marker for $C C A$. In order to determine whether the 2 proteins can be used as biliary tumor markers for CCA, we first detected the existence and the level of the 2 proteins in the cell culture supernatant of CCA cells compared with the HiBECs. The results from western blot analysis indicated that TPD52, DNAJB1, as well as TRF, were not only secreted into the CCA cell supernatant, and that the levels were higher than those of the HiBECs (Fig. 6A). Furthermore, we then analyzed the bile concentration of TPD52 and DNAJB1 proteins in 29 patients with CCA and 8 healthy individuals by western blot analysis. Of note, we found that the expression levels of TPD52 and DNAJB1 in the bile of patients with CCA were all markedly higher than those of the healthy individuals (Fig. 6B and C). As shown in Fig. 6D, TPD52 expression was higher in the patients with CCA and lower in the healthy individuals compared with TRF. These results indicated that TPD52 and DNAJB1 may be more sensitive biliary biomarkers for the clinical diagnosis of patients with CCA.

\section{Discussion}

The investigation of the proteome involved in the development of cancer has significance in the discovery of biomarkers for tumors. However, the identification of secretory proteins related to CCA remains limited. In the present study, iTRAQ labeling combined with LC-MS/MS was used to detect CCA cell-enriched secretory proteins compared with the normal biliary epithelial cell line. A total of 778 DEPs were identified and 4 upregulated proteins associated with cancer were further identified, including TPD52, DNAJB1, TACC3 and Ephrin A1. In addition, the GO database revealed cellular component, molecular functions and biological process of 778 DEPs. The signaling pathways of these proteins were analyzed using the KEGG database. Finally, following validation by RT-qPCR and western blot analysis, TPD52 and DNAJB1 were selected for further analysis.

With the progress of 'Omics' technologies, a number of technologies have been applied to CCA biomarker discovery (15). Although there are some studies available on the development of CCA biomarkers using proteomic-based approaches $(16,17)$, the identification of secretory proteins in CCA remains unknown. Thus, this study aimed to detect CCA cell-enriched secretory proteins using iTRAQ labeling combined with LC-MS/MS, and to further validate the biomarkers in CCA cell lines, tissue and bile.

Due to the limited number of bile samples, we could not use $\beta$-actin or GAPDH as a control. There is an evidence to indicate that TRF may serve as a good standard in the secreted protein (18). The findings of this study indicated that TPD52 and DNAJB1 were highly expressed tissues from patients with CCA compared with those healthy individuals compared with TRF, suggesting that TPD52 and DNAJB1 may be sensitive biliary biomarkers for the clinical diagnosis of CCA.

TPD52 is a composing member of the TPD52-like protein family, which are small coiled-coil motif bearing proteins and conserved from lower organisms to humans (19). TPD52 
Table II. Associations between the 2 tumor markers and clinical features of patients with CCA.

\begin{tabular}{|c|c|c|c|c|c|c|c|}
\hline \multirow[b]{2}{*}{ Features } & \multicolumn{3}{|c|}{ TPD52 } & \multirow[b]{2}{*}{ P-value } & \multicolumn{2}{|c|}{ DNAJB1 } & \multirow[b]{2}{*}{ P-value } \\
\hline & $\mathrm{N}$ & $\mathrm{L}$ & $\mathrm{H}$ & & $\mathrm{L}$ & $\mathrm{H}$ & \\
\hline Age (years) & & & & 0.3836 & & & 0.6742 \\
\hline$\leq 60$ & 61 & 14 & 47 & & 12 & 49 & \\
\hline$>60$ & 66 & 11 & 55 & & 15 & 51 & \\
\hline Sex & & & & 0.4191 & & & 0.9972 \\
\hline Male & 80 & 14 & 66 & & 17 & 63 & \\
\hline Female & 47 & 11 & 36 & & 10 & 37 & \\
\hline Differentiation & & & & $0.0332^{\mathrm{a}}$ & & & $0.0158^{\mathrm{a}}$ \\
\hline I, I-II, II & 78 & 20 & 58 & & 22 & 56 & \\
\hline II-III, III, III-IV & 49 & 5 & 44 & & 5 & 44 & \\
\hline Localization & & & & 0.7087 & & & 0.5042 \\
\hline Intrahepatic & 100 & 19 & 81 & & 20 & 80 & \\
\hline Extrahepatic & 27 & 6 & 21 & & 7 & 20 & \\
\hline Tumor size $(\mathrm{cm})$ & & & & 0.6811 & & & 0.6811 \\
\hline$\leq 5$ & 59 & 13 & 46 & & 13 & 46 & \\
\hline$>5$ & 58 & 11 & 47 & & 11 & 47 & \\
\hline Unknown & 10 & 1 & 9 & & 3 & 7 & \\
\hline Vessel invasion & & & & 0.3580 & & & $0.0474^{\mathrm{a}}$ \\
\hline Negative & 100 & 18 & 82 & & 25 & 75 & \\
\hline Positive & 27 & 7 & 20 & & 2 & 25 & \\
\hline T stage & & & & $0.0255^{\mathrm{a}}$ & & & $0.0002^{\mathrm{a}}$ \\
\hline $\mathrm{T} 1$ & 15 & 9 & 6 & & 11 & 4 & \\
\hline $\mathrm{T} 2$ & 39 & 11 & 28 & & 6 & 33 & \\
\hline T3 & 17 & 3 & 14 & & 5 & 12 & \\
\hline $\mathrm{T} 4$ & 4 & 0 & 4 & & 0 & 4 & \\
\hline Unknown & 52 & 2 & 50 & & 5 & 47 & \\
\hline $\mathrm{N}$ stage & & & & 0.0594 & & & $0.0021^{\mathrm{a}}$ \\
\hline No & 58 & 20 & 38 & & 24 & 34 & \\
\hline N1 & 25 & 3 & 22 & & 2 & 23 & \\
\hline Unknown & 44 & 2 & 42 & & 1 & 43 & \\
\hline M stage & & & & 0.1370 & & & 0.3436 \\
\hline M0 & 120 & 22 & 98 & & 25 & 95 & \\
\hline M1 & 7 & 3 & 4 & & 0 & 7 & \\
\hline Clinical stage & & & & $0.0042^{\mathrm{a}}$ & & & $0.0174^{\mathrm{a}}$ \\
\hline 1 & 16 & 11 & 5 & & 9 & 7 & \\
\hline 2 & 37 & 9 & 28 & & 10 & 27 & \\
\hline 4 & 17 & 4 & 13 & & 2 & 15 & \\
\hline Unknown & 57 & 1 & 56 & & 6 & 51 & \\
\hline
\end{tabular}

$\mathrm{N}$, number of patients; L, low expression; H, high expression; CCA, cholangiocarcinoma; TPD52, tumor protein D52; DNAJB1, DnaJ heat shock protein family $(\mathrm{Hsp} 40)$ member B1. ${ }^{\mathrm{a}} \mathrm{P}$-value $<0.05$ was considered to indicate a statistically significant difference.

was first identified through its overexpression in human breast cancer (20). In recent years, a variety of studies have demonstrated that TPD52 expression is increased at both the mRNA and protein level in a vast number of malignancies, such as lung squamous cell carcinoma (21), colorectal cancer (22), testicular germ cell tumor (23), prostate cancer (24) and ovarian carcinoma (25). In addition, TPD52 is associated with cellular transformation, proliferation and metastasis. It has been reported that TPD52 serves as an oncogene and plays a role in the development of several types of cancer. For example, the overexpression of TPD52 has been shown to promote cell migration and invasion by 
A

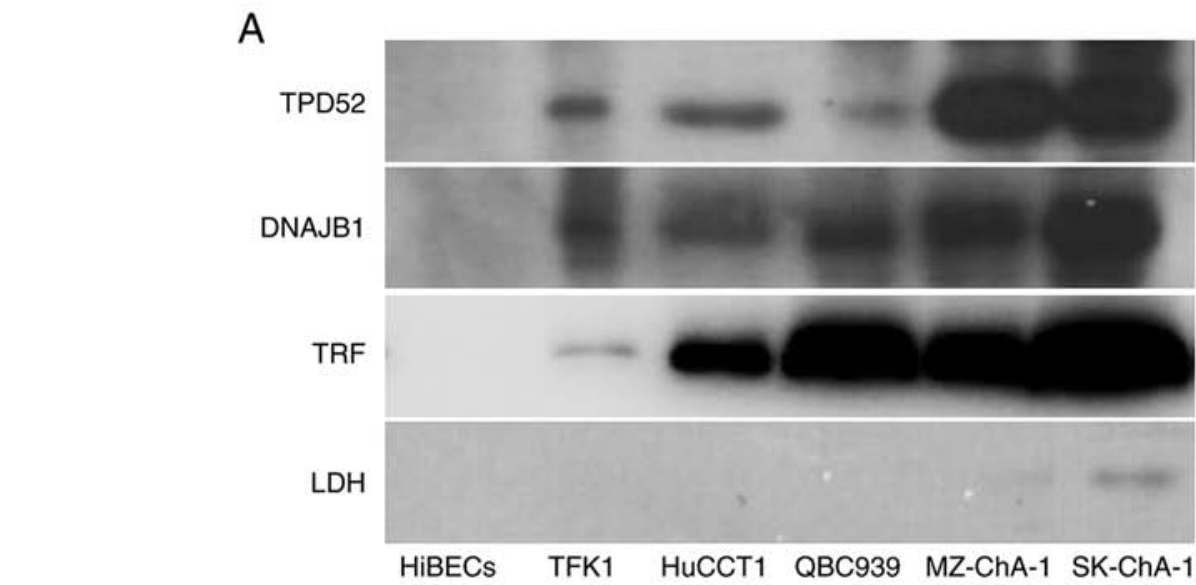

B
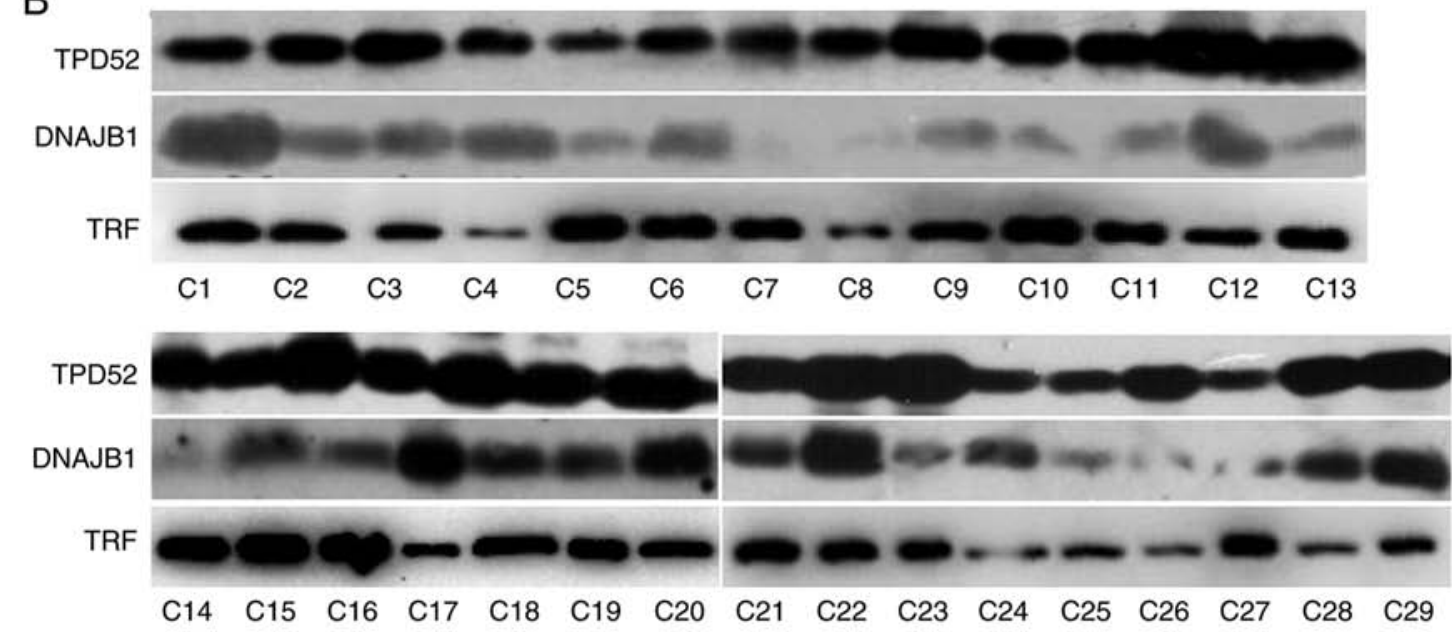

C

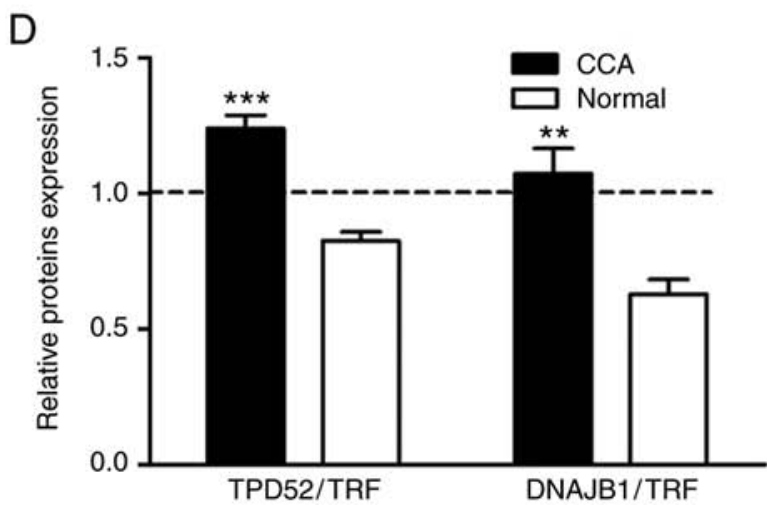

Figure 6. Validation of 2 potential bile biomarkers for CCA. (A) Western blot analysis of TPD52, DNAJB1, TRF and LDH proteins in the cell culture supernatant samples of five CCA cell lines and HiBECs. (B-D) Western blot analysis of TPD52, DNAJB1 and TRF proteins in the bile samples of 29 patients with CCA (C1-C29) and 8 healthy individuals (N1-N8). ${ }^{* *} \mathrm{P}<0.01$ and ${ }^{* * *} \mathrm{P}<0.001$. CCA, cholangiocarcinoma; TPD52, tumor protein D52; DNAJB1, DnaJ heat shock protein family (Hsp40) member B1.

inducing epithelial-mesenchymal transition and activating focal adhesion kinase-mediated integrin signaling and PI3K/Akt signaling in colorectal cells (22). In prostate cancer, the silencing of the TPD52 gene has been shown to significantly inhibit cancer cell migration and invasion (26). In the present study, we found that TPD52 was upregulated in CCA cells, tissues and bile samples. Moreover, the expression level of TPD52 was closely associated with pathological differentiation, $\mathrm{T}$ stage and clinical stage in patients with CCA. Furthermore, the overexpression of TPD52 was associated with a poor prognosis of patients with CCA.
DNAJB1, a member of the heat shock 40 protein family, has been shown to be associated with a variety of cellular processes, including the proteasome pathway (27), endoplasmic reticulum stress (28) and viral infection (29). Recently, more attention has been paid to the function of DNAJB1 in the progression of cancer. There is evidence to indicate that the DNAJB1-PRKACA chimeric transcript is elevated in $100 \%$ of fibrolamellar hepatocellular carcinoma cases, and this suggests that alterations in the expression of DNAJB1-PRKACA may contribute to tumor pathogenesis (30). In lung cancer, DNAJB1 has been shown 
to suppress MIG6 stabilization to enhance lung cancer cell proliferation (31). In the meantime, DNAJB1 also serves as an autophagy-associated protein involved in the development of tumors. DNAJB1 can target PDCD5 to inhibit p53-mediated apoptosis and enhance the proliferation of cancer cells (32). In the current study, DNAJB1 expression was found to be enhanced in CCA cells, tissues and bile samples. Furthermore, the expression level of DNAJB1was closely associated with pathological differentiation, vessel invasion, $\mathrm{T}$ stage, lymph node metastasis and clinical stage in patients with CCA. In addition, the upregulation of DNAJB1 was associated with a poor prognosis of patients with CCA.

The diagnosis of CCA from tissues poses difficulties due to its location, size and desmoplastic characteristics. Bile, a potential source of diagnostic biomarkers, can be obtained with ERCP. There is evidence to indicate that some secretory proteins can be detected in the bile of patients with biliary cancer (33). Hence, TPD52 and DNAJB1 in bile samples may be used for differential diagnoses among CCA, bile duct stones and inflammation.

Although there are interesting discoveries in this study, our research also has some limitations. First, we only detected the expression of TPD52 and DNAJB1. The pathological mechanisms of action of TPD52 and DNAJB1 in CCA warrant further investigation. Second, our results were obtained using CCA and normal biliary epithelial tissues; however, our results need to be validated using a larger sample size, including cholangitis. Third, whether TPD52 and DNAJB1 can be used as independent prognostic markers for CCA remains to be determined. Multivariate analysis may need to be done in the future. Fourth, another project with lager sample sizes will need to be performed in order to verify our findings. Finally, further studies are required to validate the pathways of DEPs in the development and progression of cancers using KEGG analysis.

In conclusion, in this study, using the iTRAQ technique, we analyzed the secretory proteins of CCA cells and a normal biliary epithelial cell line. We clearly identified TPD52 and DNAJB1 as the DEPs in CCA cells, tissues and bile samples, and these may be potential biomarkers for CCA. Furthermore, the elevated expression levels of TPD52 and DNAJB1 were strongly associated with the prognosis of patients with CCA. The findings of this study may provide new insight into the diagnosis and therapy of CCA.

\section{Acknowledgements}

Not applicable.

\section{Funding}

This study was supported by the National Natural Science Foundation of China (grant nos. 81572394 and 81201892), Xiamen Huimin Project of Science and Technology (grant no. 3502Z20174072), the Youth Nursery Foundation of the Affiliated Southeast Hospital of Xiamen University, Zhangzhou, Fujian, China (grant no. 16Y019) and the project managed by Fujian University of Traditional Chinese Medicine (grant no. XB2018127).

\section{Availability of data and materials}

All data generated or analyzed during this study are from the corresponding author on reasonable request.

\section{Authors' contributions}

DS and BC designed the study. HR and ML performed the experiments. JC, YZhou, XL and YZhan analyzed the data and processed the figures. $\mathrm{HR}$ and $\mathrm{BC}$ wrote the manuscript, and DS revised this manuscript. All authors were also involved in the discussion and revision of the manuscript.

\section{Ethics approval and consent to participate}

All procedures performed involving human participants were carried out in accordance with the ethical standards of the institutional and/or national research committee and with the 1964 Helsinki declaration and its later amendments or comparable ethical standards. This study was approved by the Ethics Committee of the First Affiliated Hospital of Xiamen University. Informed consent was obtained from all individual participants included in the study.

\section{Patient consent for publication}

Not applicable.

\section{Conflict of interest}

The authors declare that they have no competing interests.

\section{References}

1. Banales JM, Cardinale V, Carpino G, Marzioni M, Andersen JB Invernizzi P, Lind GE, Folseraas T, Forbes SJ, Fouassier L, et al: Expert consensus document: Cholangiocarcinoma: Current knowledge and future perspectives consensus statement from the european network for the study of cholangiocarcinoma (ENS-CCA). Nat Rev Gastroenterol Hepatol 13: 261-280, 2016.

2. Razumilava N and Gores GJ: Cholangiocarcinoma. Lancet 383: 2168-2179, 2014.

3. Qian Y, Yao W, Yang T, Yang Y, Liu Y, Shen Q, Zhang J, Qi W and Wang J: aPKC-l/P-Sp1/Snail signaling induces epithelial-mesenchymal transition and immunosuppression in cholangiocarcinoma. Hepatology 66: 1165-1182, 2017.

4. Zhang W and Yan LN: Perihilar cholangiocarcinoma: Current therapy. World J Gastrointest Pathophysiol 5: 344-354, 2014.

5. Khan SA, Davidson BR, Goldin RD, Heaton N, Karani J, Pereira SP, Rosenberg WM, Tait P, Taylor-Robinson SD, Thillainayagam AV, et al: Guidelines for the diagnosis and treatment of cholangiocarcinoma: An update. Gut 61: 1657-1669, 2012.

6. Coelho R, Silva M, Rodrigues-Pinto E, Cardoso H, Lopes S, Pereira P, Vilas-Boas F, Santos-Antunes J, Costa-Maia J and Macedo G: CA 19-9 as a marker of survival and a predictor of metastization in cholangiocarcinoma. GE Port J Gastroenterol 24: 114-121, 2017.

7. Voigtländer T, Metzger J, Schönemeier B, Jäger M, Mischak H, Manns M and Lankisch TO: A combined bile and urine proteomic test for cholangiocarcinoma diagnosis in patients with biliary strictures of unknown origin. United European Gastroenterol J 5: 668-676, 2017.

8. Navaneethan U, Njei B, Lourdusamy V, Konjeti R, Vargo JJ and Parsi MA: Comparative effectiveness of biliary brush cytology and intraductal biopsy for detection of malignant biliary strictures: A systematic review and meta-analysis. Gastrointest Endose 81: 168-176, 2015. 
9. Melle C, Ernst G, Schimmel B, Bleul A, Koscielny S, Wiesner A, Bogumil R, Möller U, Osterloh D, Halbhuber KJ and von Eggeling F: A technical triade for proteomic identification and characterization of cancer biomarkers. Cancer Res 64 4099-4104, 2004.

10. Ghosh D, Li Z, Tan XF, Lim TK, Mao Y and Lin Q: iTRAQ based quantitative proteomics approach validated the role of calcyclin binding protein (CacyBP) in promoting colorectal cancer metastasis. Mol Cell Proteomics 12: 1865-1880, 2013.

11. Qiao J, Fang CY, Chen SX, Wang XQ, Cui SJ, Liu XH, Jiang YH, Wang J, Zhang Y, Yang PY and Liu F: Stroma derived COL6A3 is a potential prognosis marker of colorectal carcinoma revealed by quantitative proteomics. Oncotarget 6: 29929-29946, 2015.

12. Ross PL, Huang YN and Marchese JN, Williamson B, Parker K, Hattan S, Khainovski N, Pillai S, Dey S, Daniels S, et al: Multiplexed protein quantitation in saccharomyces cerevisiae using amine-reactive isobaric tagging reagents. Mol Cell Proteomics 3: 1154-1169, 2004.

13. Huang GL, Luo Q, Rui G, Zhang W, Zhang QY, Chen QX and Shen DY: Oncogenic activity of retinoic acid receptor $\gamma$ is exhibited through activation of the Akt/NF- $\kappa \mathrm{B}$ and Wnt/ $\beta$-catenin pathways in cholangiocarcinoma. Mol Cell Biol 33: 3416-3425, 2013.

14. Livak KJ and Schmittgen TD: Analysis of relative gene expression data using real-time quantitative PCR and the 2(-Delta Delta C(T)) method. Methods 25: 402-408, 2001.

15. Silsirivanit A, Sawanyawisuth K, Riggins GJ and Wongkham C: Cancer biomarker discovery for cholangiocarcinoma: The high-throughput approaches. J Hepatobiliary Pancreat Sci 21: 388-396, 2014 .

16. Phoomak C, Park D, Silsirivanit A, Sawanyawisuth K, Vaeteewoottacharn K, Detarya M, Wongkham C, Lebrilla CB and Wongkham S: O-GlcNAc-induced nuclear translocation of hnRNP-K is associated with progression and metastasis of cholangiocarcinoma. Mol Oncol 13: 338-357, 2019.

17. Kristiansen TZ, Harsha HC, Grønborg M, Maitra A and Pandey A: Differential membrane proteomics using 180-labeling to identify biomarkers for cholangiocarcinoma. J Proteome Res 7: 4670-4677, 2008.

18. Perdomo J, Leung HHL, Ahmadi Z, Yan F, Chong JJH, Passam FH and Chong BH: Neutrophil activation and NETosis are the major drivers of thrombosis in heparin-induced thrombocytopenia. Nat Commun 10: 1322, 2019.

19. Boutros R, Fanayan S, Shehata M and Byrne JA: The tumor protein D52 family: Many pieces, many puzzles. Biochem Biophys Res Commun 325: 1115-1121, 2004.

20. Byrne JA, Tomasetto C, Garnier JM, Rouyer N, Mattei MG, Bellocq JP, Rio MC and Basset P: A screening method to identify genes commonly overexpressed in carcinomas and the identification of a novel complementary DNA sequence. Cancer Res 55: 2896-2903, 1995.

21. Kumamoto T, Seki N, Mataki H, Mizuno K, Kamikawaji K, Samukawa T, Koshizuka K, Goto Y and Inoue H: Regulation of TPD52 by antitumor microRNA-218 suppresses cancer cell migration and invasion in lung squamous cell carcinoma. Int $\mathrm{J}$ Oncol 49: 1870-1880, 2016.

22. Li J, Li Y, Liu H, Liu Y and Cui B: The four-transmembrane protein MAL2 and tumor protein D52 (TPD52) are highly expressed in colorectal cancer and correlated with poor prognosis. PLoS One 12: e0178515, 2017.
23. Alagaratnam S, Hardy JR, Lothe RA, Skotheim RI and Byrne JA TPD52, a candidate gene from genomic studies, is overexpressed in testicular germ cell tumours. Mol Cell Endocrinol 306: 75-80, 2009.

24. Rubin MA, Varambally S, Beroukhim R, Tomlins SA, Rhodes DR, Paris PL, Hofer MD, Storz-Schweizer M, Kuefer R, Fletcher JA, et al: Overexpression, amplification, and androgen regulation of TPD52 in prostate cancer. Cancer Res 64: 3814-3822, 2004

25. Byrne JA, Maleki S, Hardy JR, Gloss BS, Murali R, Scurry JP, Fanayan S, Emmanuel C, Hacker NF, Sutherland RL, et al: MAL2 and tumor protein D52 (TPD52) are frequently overexpressed in ovarian carcinoma, but differentially associated with histological subtype and patient outcome. BMC Cancer 10: 497, 2010.

26. Goto Y, Nishikawa R, Kojima S, Chiyomaru T, Enokida H, Inoguchi S, Kinoshita T, Fuse M, Sakamoto S, Nakagawa M, et al: Tumour-suppressive microRNA-224 inhibits cancer cell migration and invasion via targeting oncogenic TPD52 in prostate cancer. FEBS Lett 588: 1973-1982, 2014.

27. Yamazaki S, Uchiumi A and Katagata Y: Hsp40 regulates the amount of keratin proteins via ubiquitin-proteasome pathway in cultured human cells. Int J Mol Med 29: 165-168, 2012.

28. Lenna S, Farina AG, Martyanov V, Christmann RB, Wood TA, Farber HW, Scorza R, Whitfield ML, Lafyatis R and Trojanowska M: Increased expression of endoplasmic reticulum stress and unfolded protein response genes in peripheral blood mononuclear cells from patients with limited cutaneous systemic sclerosis and pulmonary arterial hypertension. Arthritis Rheum 65: 1357-1366, 2013.

29. Batra J, Tripathi S, Kumar A, Katz JM, Cox NJ, Lal RB, Sambhara S and Lal SK: Human heat shock protein 40 (Hsp40/DnaJB1) promotes influenza A virus replication by assisting nuclear import of viral ribonucleoproteins. Sci Rep 6: 19063, 2016.

30. Honeyman JN, Simon EP, Robine N, Chiaroni-Clarke R, Darcy DG, Lim II, Gleason CE, Murphy JM, Rosenberg BR, Teegan L, et al: Detection of a recurrent DNAJB1-PRKACA chimeric transcript in fibrolamellar hepatocellular carcinoma. Science 343: 1010-1014, 2014

31. Park SY, Choi HK, Seo JS, Yoo JY, Jeong JW, Choi Y, Choi KC and Yoon HG: DNAJB1 negatively regulates MIG6 to promote epidermal growth factor receptor signaling. Biochim Biophys Acta 1853: 2722-2730, 2015.

32. Cui X, Choi HK, Choi YS, Park SY, Sung GJ, Lee YH, Lee J, Jun WJ, Kim K, Choi KC and Yoon HG: DNAJB1 destabilizes PDCD5 to suppress p53-mediated apoptosis. Cancer Lett 357: 307-315, 2015 .

33. Rose JB, Correa-Gallego C, Li Y, Nelson J, Alseidi A, Helton WS, Allen PJ, D'Angelica MI, DeMatteo RP, Fong Y, et al: The role of biliary carcinoembryonic antigen-related cellular adhesion molecule 6 (CEACAM6) as a biomarker in cholangiocarcinoma. PLoS One 11: e0150195, 2016.

This work is licensed under a Creative Commons Attribution-NonCommercial-NoDerivatives 4.0 International (CC BY-NC-ND 4.0) License. 